EDITORIAL
Rev Colombiana Cienc Anim 2017; 9(Supl 2):241.

\title{
Colombia ciencia sin futuro
}

\author{
Colombia science without future
}

Pérez-Cordero Alexander ${ }^{1}$ Ph.D, De la ossa V Jaime ${ }^{2}$ Ph.D, Montes-Vergara Donicer ${ }^{1}$ Ph.D,

${ }^{1}$ Editor Asociado Revista Colombiana de Ciencia Animal RECIA, Universidad de Sucre, Colombia.

${ }^{2}$ Editor Revista Colombiana de Ciencia Animal RECIA, Universidad de Sucre, Colombia.

Colombia no será nada hasta que no se eduque su gente, es un país que está retrasado intelectualmente; un país que no valora la ciencia es porque nadie les ha enseñado a sus ciudadanos su valor y sus dirigentes no lo entienden, es porque no les interesa, según lo comentó GINAS, (2004). "El futuro de Colombia va a estar profunda y directamente relacionado con la capacidad que los colombianos tengamos de organizar la educación; la hija de la educación: la ciencia; y la hija de la ciencia: la tecnología-GINAS, 1993" (CORREA, 2017), hoy la ciencia en Colombia no tiene futuro; la inversión pública para ciencia disminuirá para el año 2018 en $41.5 \%$. El punto de inversión más alto fue de $\$ 430.150$ millones para el año 2013; para 2014 bajó a \$376.768 millones, en 2015 pasó a \$332.197 y en 2016 perdió otra porción y se redujo a $\$ 304.516$ millones. Este año bajó hasta $\$ 299.177$ millones y para el 2018 se prevé será el más bajo en una década, con apenas \$220.506 millones (CORREA, 2017). Las mayores repercusiones se reflejarán en el congelamiento de nuevas becas para programas doctorados y en el presupuesto para convocatorias de proyectos de investigación (EL ESPECTADOR, 2017).

Entonces qué futuro tendrán los 3976 grupos de investigación (91\% de IES) y los 8240 investigadores (86\% de IES) reconocidos por Colciencias (DEPARTAMENTO DE CIENCIAS, TECNOLOGÍA E INNOVACIÓN, 2017) en un país donde la ciencia no tiene futuro, porque se prioriza más recursos para la defensa nacional por encima de la inversión en ciencia y tecnología, y cómo se podría construir una Colombia moderna, educada, generadora de conocimiento y capaz de enfrentar retos complejos frente a hechos como el cambio climático, si en las esferas políticas no hay compromisos para que la academia y la investigación sean proyectos de vida viables para los Colombianos?.

\section{Referencias}

GINAS R. 2004. Colombia es una cenicienta que quiere ir al baile de los países desarrollados. Disponible en URL: http://www.semana.com/educacion/articulo/rodolfo-llinas-colombia-es-una-cenicienta-que-quiereir-al-baile-de-los-paises-desarrollados/385963-3

CORREA, P. 2017. El recorte a la Ciencia. Disponible en URL: http://www.elespectador.com/noticias/ ciencia/el-recorte-la-ciencia-tambien-duele-articulo-708021

EL ESPECTADOR, 2017. Disponible en URL: http://www.elespectador.com/opinion/editorial/sin-inversionen-ciencia-no-hay-futuro-articulo-708225

DEPARTAMENTO DE CIENCIAS, TECNOLOGIA E INNOVACIÓN-COLCIENCIAS. 2017. Disponible en URL: http://colciencias.gov.co/portafolio/fomento investigacion/programas/capacidades 